\title{
Expression of Human Adenosine Deaminase in Murine Hematopoietic Cells
}

\author{
JOHN W. BELMONT,* GRANT R. MACGREGOR, KAREN WAGER-SMITH, FRED A. FLETCHER, KATERI A. \\ MOORE, DIANNE HAWKINS, DEBORAH VILLALON, STEVE M.-W. CHANG, $†$ AND C. THOMAS CASKEY \\ Institute for Molecular Genetics and Howard Hughes Medical Institute, \\ Baylor College of Medicine, Houston, Texas 77030
}

Received 13 May 1988/Accepted 30 August 1988

\begin{abstract}
Multiple replication-defective retrovirus vectors were tested for their ability to transfer and express human adenosine deaminase in vitro and in vivo in a mouse bone marrow transplantation model. High-titer virus production was obtained from vectors by using both a retrovirus long terminal repeat promoter and internal transcriptional units with human c-fos and herpes virus thymidine kinase promoters. After infection of primary murine bone marrow with one of these vectors, human adenosine deaminase was detected in 60 to $85 \%$ of spleen colony-forming units and in the blood of 14 of 14 syngeneic marrow transplant recipients. This system offers the opportunity to assess methods for increasing efficiency of gene transfer, for regulation of expression of foreign genes in hematopoietic progenitors, and for long-term measurement of the stability of expression in these cells.
\end{abstract}

Adenosine deaminase (ADA) deficiency is a rare autosomal recessive condition which causes a form of severe combined immune deficiency (33). The pathophysiology of ADA deficiency has been intensively investigated and appears to involve selective toxicity of dATP for immature T lymphocytes. Alterations in methylation via inhibition of $S$-adenosylhomocysteine hydrolase have also been implicated $(19,21)$. Human ADA is encoded at a single $35-$ kilobase $(\mathrm{kb})$ locus composed of 12 exons on chromosome $20 \mathrm{q} 13(24,46,47,59)$. A full-length cDNA of 1,533 base pairs (bp) has been obtained which encodes a 362-amino-acid protein of 40.7 kilodaltons $(1,2,40)$. Bone marrow transplantation can be curative (22), and enzyme replacement has been demonstrated to improve immune function (20).

Genetic diseases, such as ADA deficiency, which directly affect the blood and reticuloendothelial cells and diseases in which circulating toxic metabolites accumulate might be treated by gene transfer into bone marrow. Hematopoietic stem cells would be the most desirable target for such gene transfer because of their extensive capacity for self-renewal and proliferation. Retrovirus vectors are very efficient vehicles for gene transfer into cultured mammalian cells (54) and have been used for transfer of foreign DNA sequences into hematopoietic progenitors $(5,6,10,15,23,30,31,35,37,38$, $42,44,61)$ and pluripotent stem cells $(13,14,18,32,36,60)$. Several replication-defective vectors have allowed expression of these introduced sequences in the differentiated progeny of infected committed progenitors and stem cells $(10,13-15,23,30,31,35-37,44,60)$, while expression with other constructions has been problematic $(38,42,61)$. Specific recognition by nuclear proteins or modification via methylation has been implicated in the failure of expression of coding sequences under transcriptional control of viral long terminal repeat (LTR) promoters in both embryonic cells and transgenic mice $(26,28,48-50,53,54,57,58)$. It remains unclear whether this type of mechanism affects expression after retrovirus-mediated gene transfer into he-

\footnotetext{
* Corresponding author.

$\dagger$ Present address: Laboratory of Molecular Genetics, National Institutes of Health, Bethesda, MD 20892.
}

matopoietic stem cells. It is possible that other mechanisms, such as poor RNA stability or processing, have been involved in the failure of expression. We have previously reported transduction of human ADA to mouse hematopoietic progenitors in vitro (5). Experiments designed to test the efficacy of that particular vector in more primitive progenitors, spleen colony-forming units (CFU-S), were positive (6), but the low infection efficiency precluded consistent repetition. Lim et al. (37) have also recently shown expression of ADA in murine CFU-S, but the infection efficiency was too low to allow long-term analysis of expression stability. Therefore, we have undertaken experiments to test vectors which might allow increased virus production and increased infection efficiency of hematopoietic progenitors. We also wished to investigate vector designs that might allow consistent expression of foreign sequences in these cells. We report here the construction and testing of 16 ADA-bearing retrovirus vectors and the results of ADA expression studies with four vectors that produced high-titer virus.

\section{MATERIALS AND METHODS}

Construction of defective retrovirus vectors. A $12.75-\mathrm{kb}$ human genomic DNA fragment containing exon 1 of the ADA gene was isolated from a library generated by cloning partially MboI-digested human fetal liver DNA into the vector EMBL3A. This insert contains approximately $2 \mathrm{~kb}$ of intron 1 and $10 \mathrm{~kb} 5^{\prime}$ of the mRNA cap site. A human ADA promoter-ADA CDNA minigene was constructed by cloning a 1,237-bp EcoRI-DdeI fragment from pADA211 (1) into the HincII site of pUC18. A HindIII-NcoI genomic DNA fragment containing $3.9 \mathrm{~kb} 5^{\prime}$ of exon 1 was ligated to the this cDNA subclone at the NcoI site (within the ATG codon). This $5.1-\mathrm{kb}$ minigene was then blunt end-ligated in both orientations into the $X h o$ I site of the N2 vector $(3,7,15,32)$ (vectors 7 and 8 in Fig. 2) and the BglII site of the FVXM (34) (M. Botchan; vectors 1 and 2 in Fig. 2) $\Delta \mathrm{e}, \Delta \mathrm{p}$, and $\Delta \mathrm{e} \Delta \mathrm{p}$ vectors (A. Bernstein; vectors 3 to 6 in Fig. 2). The human c-fos minigene was constructed by ligating a $2.25-\mathrm{kb}$ HindIII fragment from pFC1 (12) (kindly provided by $\mathrm{R}$. Vincent) containing the c-fos cap site into the NaeI site of the ADA 
cDNA (56 bp $5^{\prime}$ of the ATG). This $3.5-\mathrm{kb}$ minigene was subcloned into each vector in a manner similar to the ADA minigene (vectors 9 to 13 in Fig. 2). pXT1ADA was constructed by ligating a partially BamHI-cut ADA cDNA fragment from p7ADA $\Delta$ (a 1,237-bp EcoRI-DdeI fragment subcloned into the $H$ incII site of pUC7) to $B g$ lII-cut and calf intestinal phosphatase-treated pXT1 (8) (kindly provided by E. Wagner; contains the 5' LTR and gag region from N2, a neo gene, and a 925-bp herpes simplex virus [HSV] thymidine kinase [TK] promoter; vector 14 in Fig. 2). p $\triangle X T 1 A D A$ was made by subcloning the Sall-HindIII fragment from pXT1ADA (containing the TK-ADA minigene and the $3^{\prime}$ LTR region) into SalI-HindIII-cut p5'N2 (a subclone of the 5' LTR and gag-containing EcoRI fragment from N2 in pUC18; vector 15 in Fig. 2). p $\Delta$ NN2ADA was made by reconstructing the N2 vector without neo. A SalI-HindIII fragment from N2 (3' LTR region) was subcloned into SalI-HindIII-cut $\mathrm{p}^{\prime} \mathrm{N} 2$, and then the ADA cDNA was ligated into the unique BamHI site (vector 16 in Fig. 2).

Isolation of virus producer cell lines. $\mathrm{CsCl}$-banded plasmid DNA $(10 \mu \mathrm{g})$ from each of the vector constructions was transfected into the helper cell lines $\psi 2$ (39) (ecotropic; provided by R. Mulligan) and PA317 (44) (amphotropic; provided by A. D. Miller). In the vectors lacking neo, the plasmid was cotransfected in a 10:1 molar ratio with pSV2neo (American Type Culture Collection [ATCC]). $\psi 2$ and PA317 cell lines were maintained in Dulbecco modified eagle medium (Gibco, Grand Island, N.Y.) with $10 \%$ fetal calf serum (FCS; Gibco) at $37^{\circ} \mathrm{C}$ in $10 \% \mathrm{CO}_{2}$. Populations of transfected cells were selected in G418 $(300 \mu \mathrm{g} / \mathrm{ml})$ (Gibco), and then supernatant medium from those cells was used as a source of virus for infection of the packaging cell line conferring the opposite tropism. Individual infected clones were established either by selection in G418 (for neo-containing vectors) or by seeding at low density. Protein extracts from these clonal cell lines were checked by isoelectric focusing (IEF) for the presence of human ADA. Filtered $(0.22-\mu \mathrm{m}$ pore size) supernatant medium from the individual clones was used to infect Rat208F (A. Bernstein) target cells. After 5 days, these cells were harvested and protein extracts were analyzed by IEF. In pilot experiments there was an approximate correlation of ADA-virus titer and intensity of human ADA activity detected in the transduced target cell population. This presumably reflected an increased percentage of cells infected with the virus. Clones producing the most intense human ADA activity in the target cells were used in all subsequent experiments.

IEF analysis. Rat208F target cells were harvested from 24-well tissue culture trays (Corning Glassworks, Corning, N.Y.) by trypsinization, washed once in Hanks's balanced salt solution (Gibco), and dissolved in ADA lysis buffer (50 $\mathrm{mM} \mathrm{KHPO}_{4}$ [pH 7.0], $1.0 \mathrm{mM}$ 2-mercaptoethanol, $0.1 \%$ Triton X-100; Sigma Chemical Co., St. Louis, Mo.). The extracts were cleared by centrifugation $(13,000 \times \mathrm{g}, 15 \mathrm{~min}$, $\left.4^{\circ} \mathrm{C}\right)$ and loaded onto a prefocused pH4-5 IEF gel $(6 \%$ polyacrylamide, $0.8 \mathrm{~mm}$; International Biotechnologies, New Haven, Conn.). After focusing, the gel was stained for ADA enzyme activity by standard methods (63). The gel was then fixed, dried, and photographed.

Northern analysis and RNase A protection mapping of viral transcripts. Total cellular RNA was isolated from individual cell lines by the method of Chirgwin et al. (11). RNA $(10 \mu \mathrm{g})$ was electrophoresed through a $0.9 \%$ formaldehyde-MOPS (morpholinepropanesulfonic acid)-agarose gel. The nucleic acids were transferred, hybridized, and washed as described by Thomas (55).
RNase A protection analysis was carried out as described by Gibbs and Caskey (17). Briefly, single-stranded antisense ${ }^{32} \mathrm{P}$-labeled probe was made by in vitro transcription of $1 \mu \mathrm{g}$ of linearized ( $E c o \mathrm{RI})$ plasmid template with $\mathrm{T} 7$ polymerase. The template plasmid was constructed by subcloning an EcoRI-BamHI (-136 to +150) fragment into pTZ19R (Pharmacia, Piscataway, N.J.). The probe was hybridized to $25 \mu \mathrm{g}$ of total cellular RNA $(400 \mathrm{mM} \mathrm{NaCl}, 40 \mathrm{mM}$ PIPES [piperazine- $N, N^{\prime}$-bis(2-ethanesulfonic acid), $\mathrm{pH}$ 6.7]) overnight at $60^{\circ} \mathrm{C}$. RNA-RNA hybrids were bound to poly(U) paper and then eluted $\left(\mathrm{H}_{2} \mathrm{O}, 65^{\circ} \mathrm{C}, 10 \mathrm{~min}\right)$ before digestion with RNase A $(10 \mu \mathrm{g} / \mathrm{ml})(67 \mathrm{mM} \mathrm{NaCl}, 33 \mathrm{mM} \mathrm{LiCl}, 1 \mathrm{mM}$ EDTA, 10 $\mathrm{mM}$ Tris, $\mathrm{pH} 7.5)$. The protected strands were denatured (97\% formamide, $1 \mathrm{mM}$ EDTA, $10 \mathrm{mM}$ Tris [pH 7.5], 0.1\% sodium dodecyl sulfate, $0.001 \%$ bromophenol blue, $0.0001 \%$ xylene cyanol) and separated on a $5 \%$ acrylamide-7 M ureaTBE (Tris-borate-EDTA) sequencing gel. The gel was dried and then autoradiographed.

Bone marrow culture and transplants. Fresh bone marrow cells $\left(6 \times 10^{6}\right)$ harvested from the tibias and femurs of healthy 8- to 12-week-old C57BL/6J mice (Jackson Laboratories, Bar Harbor, Maine) were cocultivated with $6 \times 10^{6}$ irradiated $\left(1,500 \mathrm{rad},{ }^{137} \mathrm{Cs}\right.$ source; Gammacell 1000 , Atomic Energy Ltd., Zippyville, Canada) virus producer cells in Iscove modified Dulbecco medium (IMDM; Gibco) supplemented with bovine serum albumin (BSA), Fe-saturated transferrin, soybean lipids (Boehringer-Mannheim Biochemicals, Indianapolis, Ind.), $10 \%$ FCS, $10 \%$ WEHI3B(D-) (provided by R. Phillips)-conditioned medium (interleukin3), and 10\% 5637 (ATCC)-conditioned medium (interleukin$1 \alpha$, interleukin-6). After $24 \mathrm{~h}$ the nonadherent cells were removed into petri dishes for an additional $48 \mathrm{~h}$ of culture. With vectors carrying the neo gene, some of the cells were preselected in $\mathrm{G} 418(1.50 \mathrm{mg} / \mathrm{ml})$. Viable cells $\left(10^{5}\right)$ were plated into $1 \mathrm{ml}$ of semisolid methylcellulose cultures in supplemented IMDM. Cultured-cell colony-forming units (CFU-C) were counted and picked after 10 days. Irradiated (1,000 rad) syngeneic recipient animals were injected intravenously (i.v.) with between $5 \times 10^{4}$ and $5 \times 10^{5}$ viable cells for study of distinct CFU-S. Recipients were sacrificed at 14 days posttransplantation, and individual CFU-S were dissected from the surrounding stroma.

Southern analysis. High-molecular-weight DNA was isolated by standard techniques from the individual cell lines. Genomic DNA $(5 \mu \mathrm{g})$ was cut with NheI (cuts once in each of the LTRs of the vector), electrophoresed through a $0.7 \%$ TAE (Tris-acetate-EDTA)-agarose gel, and blot transferred to nylon membrane (GeneScreen Plus; Dupont, Boston, Mass.) by the method of Southern (51). ADA cDNA was labeled with $\left[{ }^{32} \mathrm{P}\right] \mathrm{dCTP}(16)$ and hybridized as described before (5). Filters were washed to a final stringency of $0.1 \times$ SSC ( $1 \times$ SSC is $0.15 \mathrm{M} \mathrm{NaCl}$ plus $0.015 \mathrm{M}$ sodium citrate) at $65^{\circ} \mathrm{C}$. The blots were exposed to Kodak XAR-5 film overnight with an intensifying screen.

The splenic tissue was disrupted with several strokes in a Dounce microhomogenizer in lysis buffer. Genomic DNA was extracted from the nuclear pellet after centrifugation by standard methods, and $10 \mu \mathrm{g}$ was cut with HindIII (cuts outside the vector) or with Bam HI (cuts once in the vector). The cut DNA was run through a $0.8 \%$ TAE-agarose gel, blotted to nylon membrane, and hybridized with random hexamer ${ }^{32}$ P-labeled ADA cDNA probe. Estimation of copy number was performed with an Amersham video analyzer (Amersham, Arlington, Ill.). Band intensities were normalized by using the endogenous mouse ADA gene as an 
P $\triangle N N 2 A D A \quad(p U C$ 19)
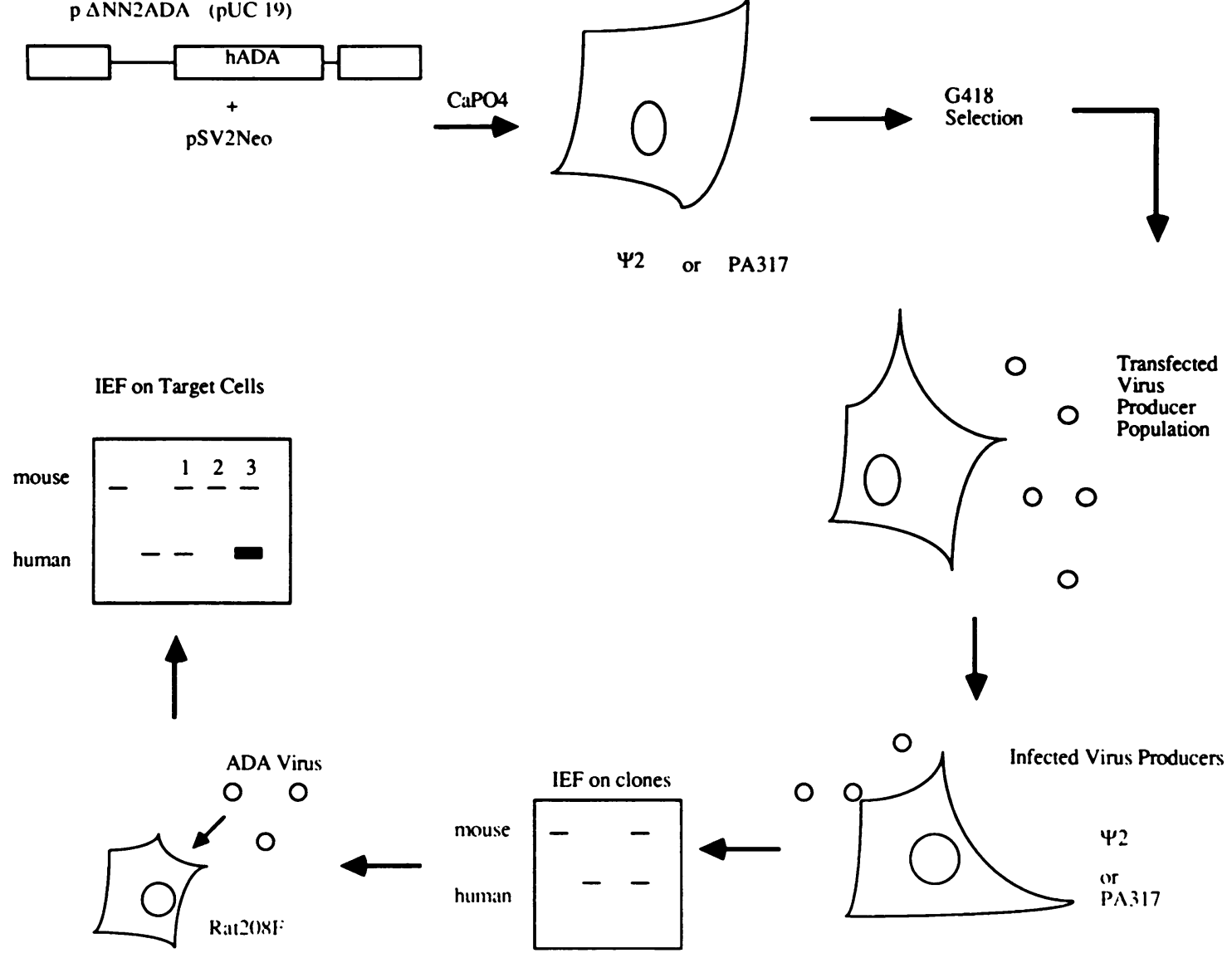

FIG. 1. Protocol for screening retrovirus vector. See Materials and Methods for details. hADA, Human ADA. Insets: IEF gel analysis was used to determine whether cloned $\psi 2$ or PA317 cell lines expressed human ADA and thus could produce ADA virus. IEF gel analysis was also used to assess the expression of human ADA in target Rat 208F cells. A high level of expression (denoted by a heavy line) was correlated with a high-titer virus preparation from an individual virus-producing clone (individual clones denoted by numbers 1 through 3).

internal standard. To allow detection of this band, the hybridization wash temperature was reduced to $55^{\circ} \mathrm{C}$.

Marker rescue assay. Supernatants from defective virus producer cell lines and serum samples were incubated with an indicator cell line (SVB-3T3). The indicator cell line was produced by transfection of NIH 3T3 (ATCC) fibroblasts with the replication-defective vector pZIPneoSV(B) (9) (provided by $\mathrm{C}$. Cepko). When infected with replication-competent virus, these cells will also package a neo-containing defective vector. After a 2-week passage, the indicator cell line supernatant was harvested and used to infect Rat $208 \mathrm{~F}$ cells. These cells were then placed in G418 for enumeration of resistant colonies. The titer of replication-competent virus was determined by serial dilution of the initial supernatant or serum sample before infection onto SVB-3T3 cells.

\section{RESULTS}

Screening of vector constructions. The protocol for the evaluation of the ADA vectors is outlined in Fig. 1. Vectors were transfected into the packaging cell lines $\psi 2$ (ecotropic) and PA317 (amphotropic). Since cell lines generated by infection have been shown to allow higher titers and more stable defective vector production (45), the transformed populations were used as a source of virus to infect the opposite packaging cell type. Clonal isolates of the infected cells were obtained and checked for expression of human
ADA. ADA-transducing virus produced from these clonal isolates was then assayed by infection of target cells. The assay was intentionally made insensitive so that vectors which either produced low titers (less than $10^{4} \mathrm{CFU} / \mathrm{ml}$ ) or expressed ADA poorly could be identified and set aside. Individual cell lines giving the highest level of transduction were then used for subsequent experiments on bone marrow infection. Sixteen retrovirus vectors were tested in this way (Fig. 2). These vectors were designed to evaluate the effect on titer and expression of three aspects of structure: (i) sequences $3^{\prime}$ of the classical $\psi$ packaging site-so-called $\mathrm{gag}^{+}$; (ii) deletions in the $3^{\prime} \mathrm{U} 3$ region (self-inactivating vectors [62, 64]); and (iii) internal transcriptional units in both orientations with respect to the vector LTR. Only vectors which contain the $\mathrm{gag}^{+}$region gave positive results in the transduction assay. The $\mathrm{gag}^{+}$region has been shown to enhance viral RNA packaging but has been associated with a high propensity for recombination to form replicationcompetent virus (7). Subsequent marker rescue assay showed that several of the packaging lines transfected with $\mathrm{gag}^{+}$vectors did produce replication-competent virus. The titer of the virus in the $\mathrm{p} \Delta \mathrm{NN} 2 \mathrm{ADA}$ (vector 16 in Fig. 2) line was determined to be $10^{4}$ infectious units per ml.

The human ADA promoter-containing constructs proved to be unstable, so that although very high titers of neotransducing virus $\left(1 \times 10^{6}\right.$ to $\left.5 \times 10^{6} \mathrm{G} 418^{\mathrm{r}} \mathrm{CFU} / \mathrm{ml}\right)$ were 


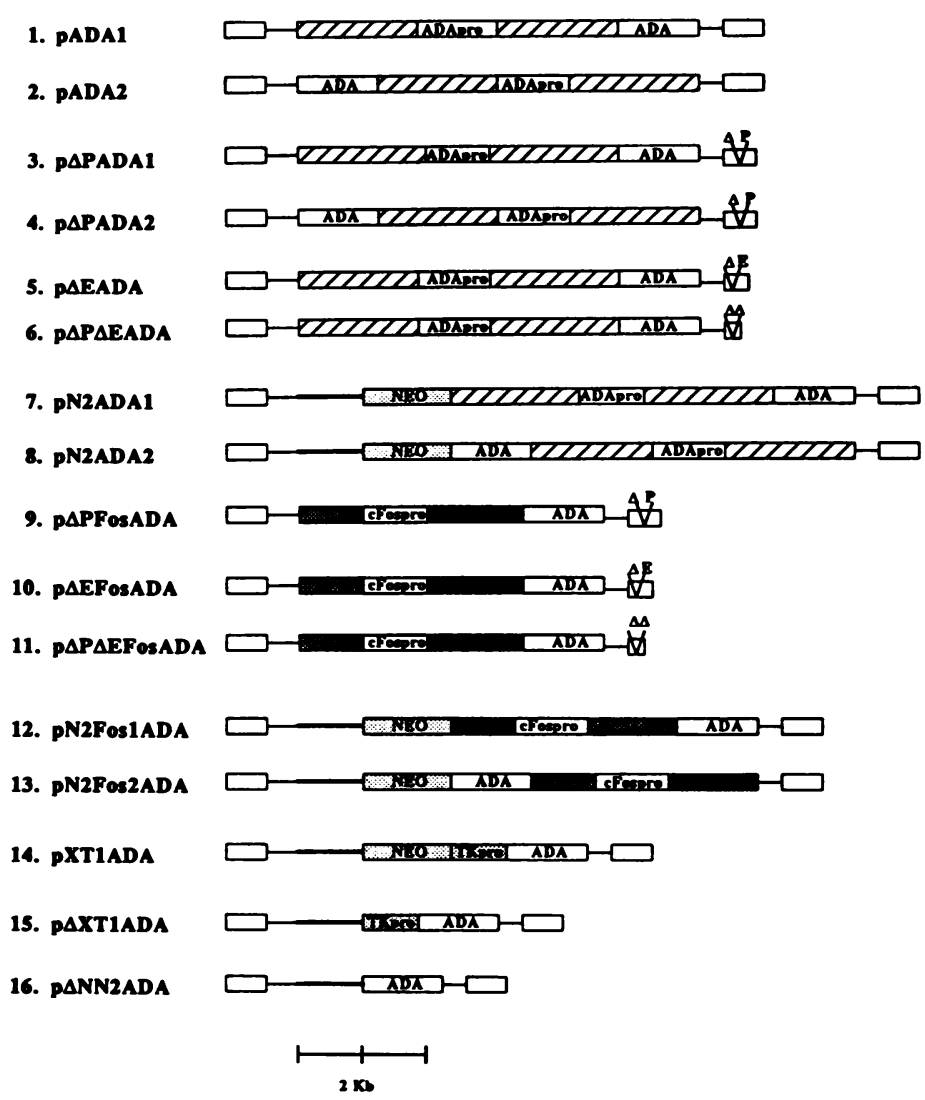

\begin{tabular}{|c|c|c|}
\hline \multicolumn{3}{|c|}{ ADA Expression } \\
\hline \multicolumn{2}{|c|}{ Transfection Infection } & Transduction \\
\hline+ & - & - \\
\hline+ & - & - \\
\hline+ & NA & - \\
\hline+ & NA & - \\
\hline+ & NA & - \\
\hline+ & NA & - \\
\hline+ & + & - \\
\hline+ & - & - \\
\hline+ & NA & - \\
\hline+ & NA & - \\
\hline+ & NA & - \\
\hline+ & + & - \\
\hline+ & + & + \\
\hline+ & + & + \\
\hline+ & + & + \\
\hline+ & + & + \\
\hline
\end{tabular}

FIG. 2. Retrovirus vector constructs. The heavy line (vectors 7,8 , and 12 to 16 ) indicates the gag $^{+}$region (nucleotides 564 to 1038 in Moloney virus). Open boxes denote the Moloney virus LTR. Plasmid vector DNAs were transfected into the packaging cell lines $\psi 2$ and PA317. Virus produced from these cells was used to infect the packaging cell line of the opposite tropism. Those vectors which produced virus titers sufficient to be detected by IEF on unselected populations were developed further. Clonal isolates from infected populations were tested for transduction of virus to the target cell line Rat208F. pro, Promoter; NA, not applicable. Hatched boxes correspond to the human ADA promoter and 5 -flanking sequences (ca. $3.9 \mathrm{~kb}$ from the transcription initiation site); shaded boxes denote the c-fos promoter and enhancer sequences (12).

found, no transduction of ADA activity was observed. One potential explanation for this may be its relatively large size (9.4-kb mRNA). Vectors containing a shorter ADA promoter are currently being evaluated. The orientation of the c-fos minigene appeared to be important. Infection of $\psi 2$ cells with the forward-orientation construct (same direction of transcription as the LTR) did not allow ADA transduction, although the reverse orientation did. This might be explained by the presence of cryptic splice donor or acceptor signals, poly(A) addition sites, or other interactions between these sequences and the vector LTRs causing instabilities in the vector containing the forward-orientation c-fos promoter minigene. In contrast, the HSV TK promoter constructions produce virus well. Thus, orientation can play an unpredictable role in individual constructs.

Southern and Northern analyses of selected virus-producing lines and infected clones of Rat $208 \mathrm{~F}$ cells indicated no major rearrangements in their integrated and expressed forms (Fig. 3a and b). Interestingly, we detected only one species of human ADA mRNA in the cells infected with the $\mathrm{p} \Delta \mathrm{NN} 2 A D A$ virus. The comparable parent construction, N2, which contains neo, produces two mRNAs, one full length and the other spliced (3). The possible utilization of an alternative cryptic splice acceptor in p $\triangle N$ N2ADA is being further evaluated by RNase protection analysis.

Infection of murine hematopoietic cells. The four hightiter viruses (designated pN2Fos2ADA, pXT1ADA, p $\Delta X T 1$ $A D A$, and $p \triangle N N 2 A D A$; vectors 13 to 16 in Fig. 2) were subsequently used to infect primary mouse bone marrow cells. Infection was obtained by $24 \mathrm{~h}$ of cocultivation with irradiated virus producer lines. Infected marrow was either plated in semisolid culture for enumeration of G418-resistant CFU-C or injected into irradiated recipients. Some recipients received graded doses of the marrow cells so that discrete CFU-S could be studied. Other animals received reconstituting doses $\left(1 \times 10^{6}\right.$ to $3 \times 10^{6}$ viable cells $)$ to allow long-term studies of human ADA expression. The results of these experiments are summarized in Table 1.

Two vectors, pN2Fos2ADA (vector 13) and pXT1ADA (vector 14), containing the c-fos promoter and the HSV TK promoters, respectively, failed to express human ADA in CFU-C or CFU-S even though these viruses worked well in tissue culture fibroblasts and even though the infection efficiency was adequate. Both vectors expressed neo from the LTR promoter and conferred G418 resistance to between 1 and $20 \%$ of CFU-C. In contrast, CFU-C infected with the 


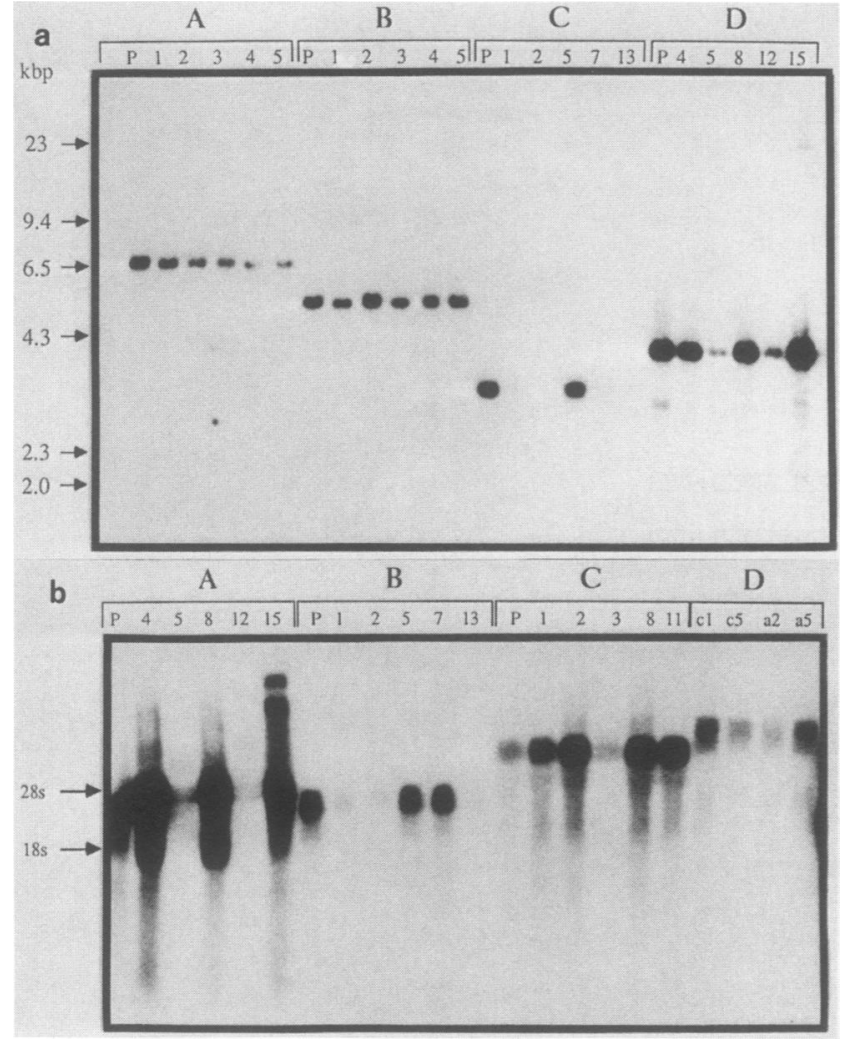

FIG. 3. (a) Southern analysis on ADA vector-infected cells. Group A, vector 13, pN2Fos2ADA; group B, vector 14, pXT1ADA; group $C$, vector $16, p \Delta N N 2 A D A$; group $D$, vector $15, p \Delta X T 1 A D A$. The parent virus producer line $(\mathrm{P})$ and five infected clones are shown. Genomic DNA from infected Rat208F clones was cut with NheI (cuts in the vector LTRs), blotted, and then probed with a radiolabeled ADA cDNA. (b) Northern analysis of infected cells. Group A, vector 15, $\mathrm{p} \triangle \mathrm{XT1} 1 \mathrm{ADA}$; group $\mathrm{B}$, vector $16, \mathrm{p} \Delta \mathrm{NN} 2 \mathrm{ADA}$; group C, vector 14, pXT1ADA; group D, vector 13, pN2Fos2ADA. Lanes correspond to the parent virus producer line $(\mathrm{P})$ and five infected clones. Total RNA was separated on a formaldehydeMOPS-agarose denaturing gel, and then human ADA-containing mRNA was detected with an ADA cDNA probe.

virus by using the Moloney virus LTR promoter ( $\mathrm{p} \triangle \mathrm{NN} 2 \mathrm{ADA}$, vector 16 ) or the HSV TK promoter and lacking the neo gene (p $\Delta X T 1 A D A$, vector 15$)$ expressed human ADA. This enzyme activity could be detected in pooled $\mathrm{CFU}-\mathrm{C}$ in the absence of selection, indicating very high infection efficiency. Likewise, when individual CFU-S were analyzed, infection efficiencies of between 50 and $85 \%$

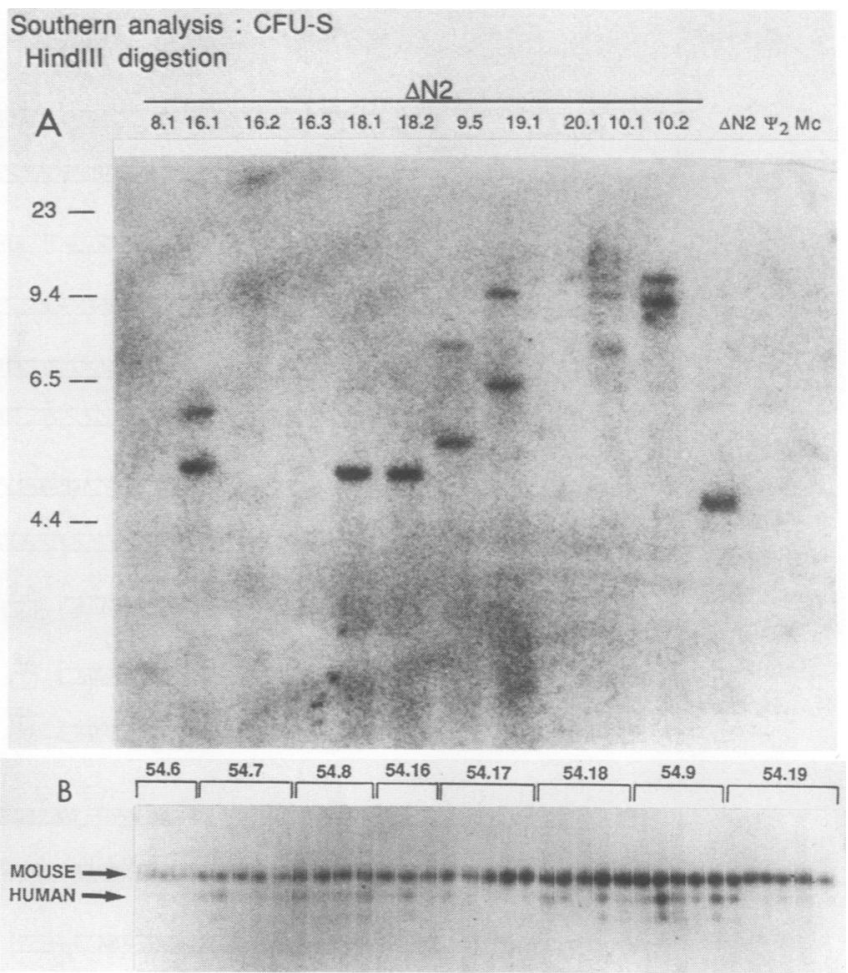

FIG. 4. (A) Southern analysis of CFU-S infected with the p $\triangle N N 2 A D A$ vector. Genomic DNA was extracted from the nuclear pellets of homogenized individual CFU-S and cut with HindIII (does not cut within the provirus). Human ADA sequences were detected with a radiolabeled ADA cDNA probe. Lanes correspond to DNA isolated from CFU-S. $\Delta \mathrm{N} 2$, Control infected cell line; $\psi 2$, parent packaging cell line; MC, control mouse splenic DNA. (B) Expression of human ADA in CFU-S. Protein extracts from individual 14-day CFU-S taken from recipient animals injected with $5 \times 10^{4}$ p $\triangle N$ N2ADA virus-infected marrow cells were then run on IEF gels as described in Materials and Methods. Each lane contains one CFU-S; bracketed areas indicate individual animals. The positions of murine and human ADA are shown. Lane numbers designate mouse recipient and CFU-S samples.

were observed based on Southern analysis (Fig. 4A) and expression of human ADA (Fig. 4B). There was a $100 \%$ correlation between integration events and expression with both of these vectors in this experiment. The restriction enzyme HindIII does not cut within the provirus, so each band on the Southern blot corresponds to a discrete integration event. The fact that some of the CFU-S had multiple integrations and some had none suggests heterogeneity in the infectability of these cells. In a series of three experi-

TABLE 1. Infection and expression of ADA-transducing retrovirus vectors in murine hematopoietic cells

\begin{tabular}{|c|c|c|c|c|}
\hline \multirow{2}{*}{ Vector $^{a}$ (vector no.) } & \multicolumn{2}{|c|}{ In vitro } & \multicolumn{2}{|r|}{ In vivo ${ }^{b}$} \\
\hline & $\begin{array}{c}\mathrm{G}^{418^{r}} \mathrm{CFU}^{c} \\
(\%)\end{array}$ & $\mathrm{IEF}^{d}$ & 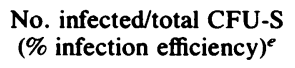 & $\begin{array}{c}\text { No. expressing hADA/total infected CFU-S } \\
\text { (\% expression efficiency) }\end{array}$ \\
\hline $\begin{array}{l}\text { pN2Fos2ADA (13) } \\
\text { pXT1ADA (14) } \\
\text { p } \Delta \text { XT1ADA (15) } \\
\text { p } \Delta \text { NN2ADA (16) }\end{array}$ & $\begin{array}{l}8-20 \\
1.6-8.5 \\
\text { NA }{ }^{f} \\
\text { NA }\end{array}$ & $\begin{array}{l}\text { Negative } \\
\text { Negative } \\
\text { Positive } \\
\text { Positive }\end{array}$ & $\begin{array}{l}2 / 35(6) \\
11 / 18(61) \\
9 / 15(60) \\
31 / 45(69)\end{array}$ & $\begin{array}{c}0 / 2 \\
0 / 11 \\
9 / 9 \\
24 / 31\end{array}$ \\
\hline
\end{tabular}

${ }^{a}$ See Fig. 2 for description of vectors.

${ }^{b}$ Discrete (CFU-S) cells or whole spleens were marrow-reconstituted mice were analyzed as described in the legend to Fig. 4.

${ }^{c}$ Infected bone marrow cells were plated in supplemented IMDM with $0.5 \%$ methylcellulose as described previously (9). CFU were counted at 10 days.

${ }^{d}$ Individual CFUs were picked from semisolid cultures and pooled, and the protein extracts were analyzed for the presence of human ADA by use of IEF. For vectors 13 and 14 , these were G418 CFU, but for vectors 15 and 16 , the CFUs were produced under nonselective conditions.

e The number of CFU-S bearing the ADA-containing provirus was determined by Southern analysis of genomic DNA as described in the legend to Fig. 4 .

$f$ NA, G418 selection not applicable to vectors without the neo gene. 


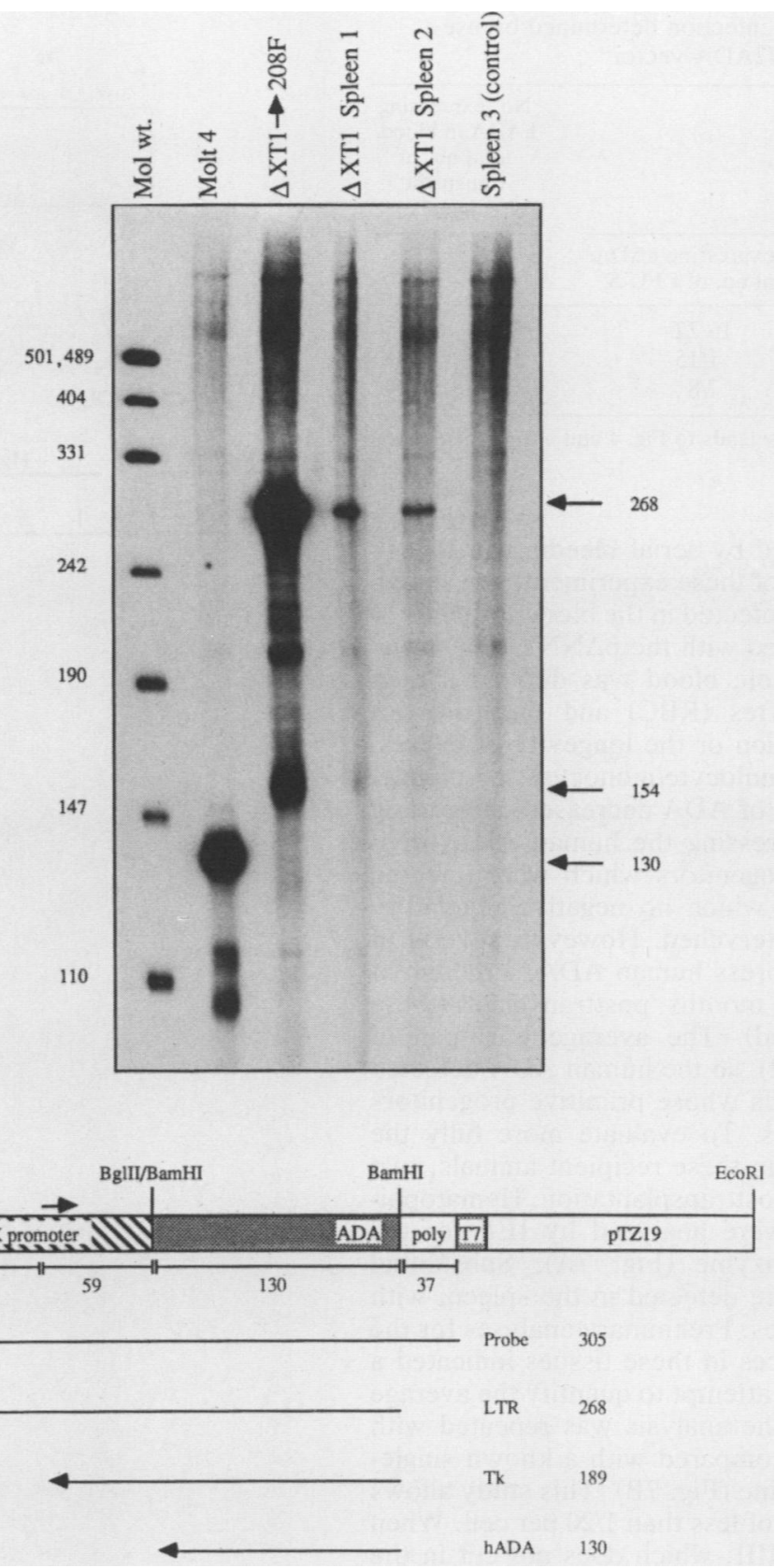

FIG. 5. RNase A protection analysis on spleen RNA from animals infected with the p $\triangle X T 1 A D A$ vector. Single-stranded RNA antisense probe was synthesized in vitro by use of the T7 promoter (T7) from a linearized (EcoRI-cut) plasmid (pTZ19). The total probe length is 305 nucleotides, including a part of the TK promoter, ADA cDNA to the BamHI site (position +150), and the pTZ19 polylinker (poly). A transcript initiated in the LTR would be expected to protect a fragment of 268 nucleotides. A transcript initiated in the TK promoter would be predicted to protect a transcript of 189 nucleotides (although a 154-nucleotide transcript was observed). The normal hADA transcript should protect only the ADA coding sequence (130 nucleotides). Lanes: 1, molecular weight markers; 2 , Molt4 cells (human T cell leukemia line, ATCC); 3, p $\triangle X T 1 A D A$-infected Rat208F cells; 4, spleen cells from marrow-reconstituted animal 114 days posttransplantation with p $\Delta$ XT1ADAinfected marrow; 5, p $\Delta$ XT1ADA-infected animal 2;6, control spleen.

ments (Table 2) with the p $\Delta$ NN2ADA vector, we also observed variation in expression efficiency. In the second experiment, there was adequate infection efficiency (approximately $60 \%$ ), as determined by provirus integration, but very low expression efficiency in CFU-S. This indicates that beyond the variability in infectability of these cells, there is also biological variation in the regulation of expression with the same vector sequences.

To determine whether expression of human ADA in the spleens of animals transplanted with the $\mathrm{p} \triangle \mathrm{XT1ADA}$ vectorinfected marrow originated from the LTR or the HSV TK promoter, an RNase A protection study was performed (Fig. 5). This suggested that the predominant RNA species originated in the LTR and that the HSV TK promoter contributed relatively little to production of human ADA mRNA.

Expression of human ADA in blood of marrow-reconstituted animals. Following transplantation with infected marrow, the presence of human ADA in marrow-reconstituted 
TABLE 2. Bone marrow infection determined by use of the $\mathrm{p} \Delta \mathrm{NN} 2 \mathrm{ADA}$ vector ${ }^{a}$

\begin{tabular}{ccccccc}
\hline Expt & \multicolumn{2}{c}{ CFU-S } & \multicolumn{3}{c}{$\begin{array}{c}\text { No. expressing } \\
\text { hADA in blood/ } \\
\text { total no. of } \\
\text { transplant } \\
\text { recipients: }\end{array}$} \\
\cline { 2 - 3 } \cline { 6 - 7 } & $\begin{array}{c}\text { No. infected/total } \\
\text { no. of CFU-S }\end{array}$ & $\begin{array}{c}\text { No. expressing hADA } \\
\text { total no. of CFU-S }\end{array}$ & & 4 & 12 \\
\hline 1 & $16 / 22(72)$ & $16 / 22$ & & $5 / 5$ & $2 / 5$ \\
2 & $8 / 15(61)$ & $1 / 15$ & & $5 / 5$ & $0 / 5$ \\
3 & $7 / 8(85)$ & $7 / 8$ & & $4 / 4$ & $4 / 4$ \\
\hline
\end{tabular}

${ }^{a}$ See Materials and Methods and legends to Fig. 4 and 6 for experimental details.

recipient mice was monitored by serial bleeding at 2-week intervals. The results of one of these experiments are shown in Fig. 6. Human ADA was detected in the blood in $100 \%$ (14 of 14) of the mice transplanted with the p $\triangle N N 2 A D A$ virus. The ADA enzyme from whole blood was derived almost entirely from the erythrocytes (RBC) and thus did not indicate the level of expression or the longevity of expression in the lymphocyte, granulocyte/monocyte, or platelet lineages. Over time the level of ADA decreased, suggesting that the cells originally expressing the human ADA originated from more mature progenitors which were infected with higher efficiency or in which no negative regulatory effects on expression had intervened. However, several of the animals continued to express human ADA, although at diminished levels, up to 6 months posttransplant (these animals were then sacrificed). The average life span of murine $R B C$ is 45 days $(4,62)$, so the human ADA detected probably originated from cells whose primitive progenitors were infected with the virus. To evaluate more fully the distribution of human ADA in these recipient animals, two were sacrificed at 12 weeks posttransplantation. Hematopoietic and lymphoid tissues were analyzed by IEF for the presence of the human enzyme (Fig. 7A). Substantial amounts of human ADA were detected in the spleen, with lesser amounts in other tissues. Preliminary analyses for the presence of proviral sequences in these tissues indicated a very low copy number. In an attempt to quantify the average number of copies per cell, the analysis was repeated with various quantities of DNA compared with a known singlecopy provirus insertion cell line (Fig. 7B). This study allows estimation of a copy number of less than $1 / 20$ per cell. When the DNA was cut with HindIII, which does not cut in the vector, only a single band was observed. A band of similar molecular weight was detected in the bone marrow of this animal (not shown). This indicates that at least one multipo-

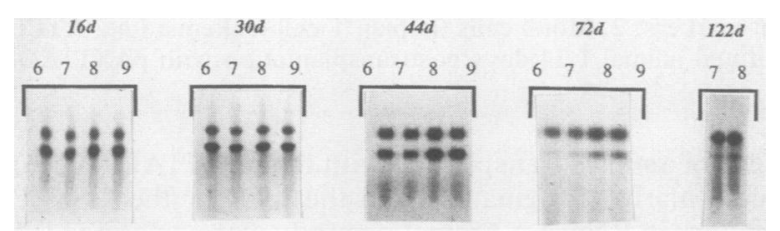

FIG. 6. Expression of human ADA in the blood of marrowreconstituted recipients. Infected viable bone marrow cells $\left(10^{6}\right)$ were injected i.v. into lethally irradiated recipients. These animals were bled at intervals posttransplantation, and protein extracts from blood cells were analyzed by IEF. Time after transplantation (in days) is indicated above the panels. This set of animals corresponds to those used in experiment 3 of Table 2 . Lane numbers designate individual bone marrow transplant recipient animals from experiment 3 in Table 2.

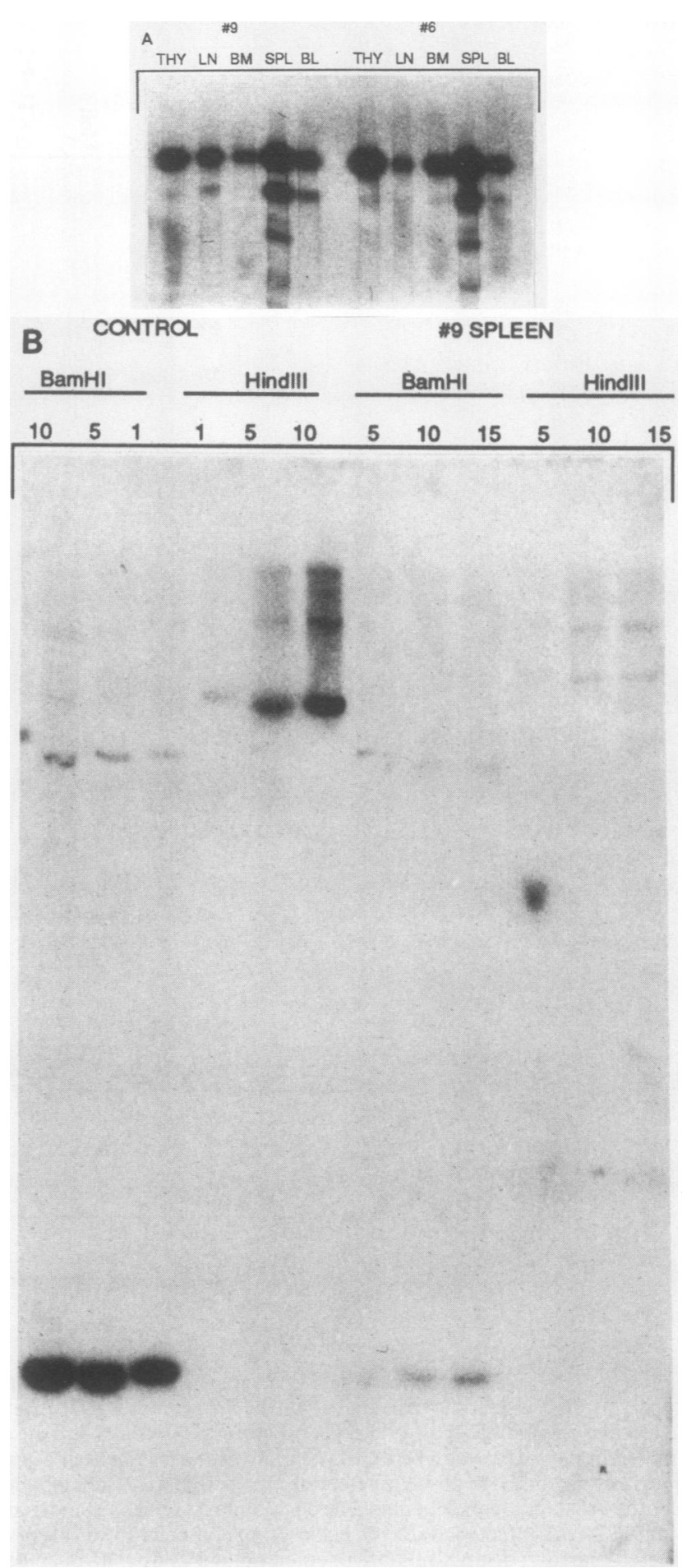

FIG. 7. (A) Expression of human ADA in tissues from animals reconstituted with marrow infected with the $\mathrm{p} \triangle \mathrm{NN} 2 \mathrm{ADA}$ vector. Thy, Thumus; LN, lymph node; BM, bone marrow; SPL, spleen; BL, blood. Animals 6 and 9 are the same as those designated in Fig. 6 and were part of experiment 3 in Table 2. (B) Southern analysis on the spleen of animal 9. Genomic DNAs from the vector producer cell line $\mathrm{p} \triangle \mathrm{NN} 2 \mathrm{ADA}$ and from the spleen of the long term recipient animal 9 were digested with either BamHI or HindIII. The blotted DNAs were then probed with an ADA cDNA. The wash stringency was adjusted to allow detection of the endogenous mouse gene to provide an internal control for quantitation. Band intensities were measured with an Amersham video imaging system. Lane numbers indicate the micrograms of DNA loaded. 
tent progenitor was infected with the provirus, and its progeny may be the source of the observed ADA activity. Because the vector-producing cell lines also produced replication-competent virus, it is also formally possible that replication-competent virus introduced at the time of infection with the ADA-transducing defective virus allowed spread of the defective virus in vivo. Serial assay of serum from the $\mathrm{p} \Delta \mathrm{NN} 2 \mathrm{ADA}$ and $\mathrm{p} \triangle \mathrm{XT} 1 \mathrm{ADA}$ recipients by marker rescue assay indicated viremia with the replication-competent virus in all these animals, including those animals which expressed human ADA only transiently (data not shown). The titer of this virus in the serum of one animal (no. 9 from the third experiment, Table 2, Fig. 6) was determined to be $10^{2}$ infectious units per ml. ADA-transducing virus was not detected by IEF analysis on the indicator cell lines or by immunohistochemical staining for human ADA (a technique which can identify single infection events; manuscript in preparation).

\section{DISCUSSION}

These experiments demonstrate long-term expression of a human disease-related gene product in mouse hematopoietic cells. The results are consistent with previous published reports of expression of neomycin phosphotransferase in these cells $(15,32)$ with the parent vector N2. Recently, Dzierzak et al. (14) reported low-level expression of human $\beta$-globin in mouse blood cells and were able to demonstrate expression in the progeny of infected pluripotent stem cells. These experiments also demonstrated expression of neo in lymphoid cells under the control of the viral LTR promoter. Lim et al. (37) have also recently shown that vectors which utilize the phosphoglyceratekinase promoter can be used to obtain expression of human ADA in CFU-S. Together, these results provide direction and encouragement for the refinement of retrovirus expression vectors.

The results presented here suggest that the Moloney LTR promoter has no adverse effect on expression in murine hematopoietic progenitors. However, if in vivo spread of the defective virus occurs, the observed expression may have originated from infection of more mature cells, in which the LTR is known to function well. We do not believe that in vivo spread contributes much to human ADA expression in the blood for the following reasons: (i) the orderly and consistent reduction in expression seen in all animals at ca. 10 to 12 weeks postreconstitution; (ii) the stability of expression observed beyond 12 weeks in individual animals without apparent fluctuation; (iii) the presence of replicationcompetent virus in animals failing to express human ADA in the blood; and (iv) the lack of multiple, less-than-single-copy insertions in individual CFU-S. Definitive proof awaits repetition of these experiments with virus preparations that are free of replication-competent virus. The availability of a new packaging cell line which splits the gag-pol and env genes (41) should aid in this. The expression from LTR promoter vectors in hematopoietic cells contrasts with the poor expression from this promoter observed in embryonal carcinoma cells, early mouse embryo cells, and retrovirus transgeneic animals $(26,28,48-50,52,53,57,58)$. The regulation of expression in the differentiated progeny of true pluripotent stem cells may, however, be governed by the same mechanisms which restrict expression in the transgenic animals. This problem can be approached by further analysis of the types of vectors which are expressed in embryonal carcinoma cells and comparison with those that are expressed in the differentiated progeny of infected hematopoietic stem cells.
Further studies will be directed toward the achievement of consistent levels of expression and tissue-specific regulated expression. Inclusion of natural splice signals and tissuespecific enhancers may be of importance. Obtaining consistent and efficient infection of stem cells is another important goal. Further experiments will focus on optimization of stem cell infection by enrichment with monoclonal antibodies and cell sorting and by hormonal stimulation. The recent description of growth factors which appear to directly affect very primitive lymphoid and myeloid progenitors $(25,27)$ suggests that these cells might be propagated in vitro for infection and drug selection protocols. The nature of the cell surface receptor for viral adsorption remains unknown (29), but it may be possible to increase infection efficiency by modulating receptor density via hormonal stimulation of these cells. Molecular characterization of this receptor as well as a more detailed understanding of the most important factors governing "infectability" would be very desirable. We are optimistic that improvements can be made that will allow routine exploitation of this set of methods for analysis of hematopoiesis and eventually for the therapy of human ADA deficiency.

\section{ACKNOWLEDGMENTS}

This work was supported by the Howard Hughes Medical Institute (HHMI) and by Public Health Service grant HD21452 from the National Institutes of Health and a grant from the Cystic Fibrosis Foundation. G.R.M. is the recipient of an Arthritis Foundation postdoctoral fellowship; J.W.B. is an Assistant Investigator and CTC is an Investigator at HHMI.

We thank Jenny Henkel-Tigges and Michelle Rives for technical assistance and Elsa Perez for help in preparation of the manuscript. We also thank $H$. Zogbi and J. Noebels for help with video quantitation of Southern analyses and J. Dick and L. Donehower for useful discussions during the completion of these studies.

\section{LITERATURE CITED}

1. Adrian, G. S., D. A. Wiginton, and J. J. Hutton. 1984. Structure of adenosine deaminase mRNAs from normal and adenosine deaminase-deficient human cell lines. Mol. Cell. Biol. 4:17121717 .

2. Akeson, A. L., D. A. Wiginton, J. C. States, C. M. Perme, M. R. Dusing, and J. J. Hutton. 1987. Mutations in the human adenosine deaminase gene that affect protein structure and RNA splicing. Proc. Natl. Acad. Sci. USA 84:5947-5951.

3. Armentano, D., S. F. Yu, P. W. Kantoff, T. von-Ruden, W. F. Anderson, and E. Gilboa. 1987. Effect of internal viral sequences on the utility of retroviral vectors. J. Virol. 61:1647-1650.

4. Bannerman, R. M. 1983. Hematology, p. 293-312. In H. L. Foster, J. D. Small, and J. G. Fox (ed.), The mouse in biomedical research, vol. III. Academic Press, New York.

5. Belmont, J. W., J. Henkel-Tigges, S. M. Chang, K. WagerSmith, R. E. Kellems, J. E. Dick, M. C. Magli, R. A. Phillips, A. Bernstein, and C. T. Caskey. 1986. Expression of human adenosine deaminase in murine haematopoietic progenitor cells following retroviral transfer. Nature (London) 322:385-387.

6. Belmont, J. W., J. Henkel-Tigges, K. Wager-Smith, S. M.-W. Chang, and C. T. Caskey. 1987. Transfer and expression of human adenosine deaminase gene in murine bone marrow cells, p. 963-972. In R. P. Gale and R. Champlin (ed.), Progress in bone marrow transplantation. Alan R. Liss, Inc., New York.

7. Bender, M. A., T. D. Palmer, R. E. Gelinas, and A. D. Miller. 1987. Evidence that the packaging signal of Moloney murine leukemia virus extends into the gag region. J. Virol. 61:16391646.

8. Boulter, C. A., and E. F. Wagner. 1987. A universal retroviral vector for efficient constitutive expression of exogenous genes. Nucleic Acids Res. 15:7194.

9. Cepko, C. L., B. E. Roberts, and R. C. Mulligan. 1984. Construction and applications of a highly transmissible murine 
retrovirus shuttle vector. Cell 37:1053-1062.

10. Chang, S. M., K. Wager-Smith, T. Y. Tsao, J. Henkel-Tigges, S. Vaishnav, and C. T. Caskey. 1987. Construction of defective retrovirus containing the human hypoxanthine phosphoribosyltransferase cDNA and its expression in cultured cells and mouse bone marrow. Mol. Cell. Biol. 7:854-863.

11. Chirgwin, J. M., A. E. Przybyla, R. J. MacDonald, and W. J. Rutter. 1979. Isolation of biologically active ribonucleic acid from sources enriched in ribonuclease. Biochemistry 18:5294 5299.

12. Deschamps, J., F. Meijlink, and I. M. Verma. 1985. Identification of a transcriptional enhancer element upstream from the proto-oncogene fos. Science 230:1174-1177.

13. Dick, J. E., M. C. Magli, D. Huszar, R. A. Phillips, and A. Bernstein. 1985. Introduction of a selectable gene into primitive stem cells capable of long-term reconstitution of the hemopoietic system of W/Wv mice. Cell 42:71-79.

14. Dzierzak, E. A., T. Papayannopoulou, and R. C. Mulligan. 1988. Lineage-specific expression of a human beta-globin gene in murine bone marrow transplant recipients reconstituted with retrovirus-transduced stem cells. Nature (London) 331:35-41.

15. Eglitis, M. A., P. Kantoff, E. Gilboa, and W. F. Anderson. 1985. Gene expression in mice after high-efficiency retroviral-mediated gene transfer. Science 230:1395-1398.

16. Feinberg, A. P., and B. Vogelstein. 1983. A technique for radiolabeling DNA restriction endonuclease fragments to high specific activity. Anal. Biochem. 132:6-13.

17. Gibbs, R. A., and C. T. Caskey. 1987. Identification and localization of mutations at the Lesch-Nyhan locus by ribonuclease A cleavage. Science 236:303-305.

18. Hawley, R. G., L. Covarrubias, T. Hawley, and B. Mintz. 1987. Handicapped retroviral vectors efficiently transduce foreign genes into hematopoietic stem cells. Proc. Natl. Acad. Sci. USA 84:2406-2410.

19. Hershfield, M. 1979. Apparent suicide inactivation of human lymphoblast $S$-adenosylhomocysteine hydrolase by $2^{\prime}$-deoxyadenosine and adenine arabinoside. J. Biol. Chem. 254:22-25.

20. Hershfield, M. S., R. H. Buckley, M. L. Greenberg, A. L. Melton, R. Schifi, C. Hatem, J. Kurtzberg, M. L. Markert, R. H. Kobayashi, A. L. Kobayashi, and A. Auchowski. 1987. Treatment of adenosine deaminase deficiency with polyethylene glycol-modified adenosine deaminase. N. Engl. J. Med. 316: 589-596.

21. Hershfield, M. S., and N. M. Kredich. 1978. S-Adenosylhomocysteine hydrolase is an adenosine binding protein: a target for adenosine toxicity. Science 202:757-760.

22. Hirshhorn, R., V. Roegner-Maniscalco, L. Kuritsky, and F. Rosen. 1981. Bone marrow transplantation only partially restores purine metabolites to normal in adenosine deaminasedeficient patients. J. Clin. Invest. 68:1387-1393.

23. Hock, R. A., and A. D. Miller. 1986. Retrovirus-mediated transfer and expression of drug resistance genes in human haematopoietic progenitor cells. Nature (London) 320:275-277.

24. Honig, J., F. Martiniuk, P. D'Eustachio, C. Zamfirescu, R. Desnick, K. Hirschhorn, L. R. Hirschhorn, and R. Hirschhorn. 1984. Confirmation of the regional localization of the genes for human acid alpha-glucosidase (GAA) and adenosine deaminase (ADA) by somatic cell hybridization. Ann. Hum. Genet. 48:4956.

25. Hunt, P., D. Robertson, D. Weiss, D. Rennick, F. Lee, and 0. Witte. 1987. A single bone marrow-derived stromal cell type supports the in vitro growth of early lymphoid and myeloid cells. Cell 48:997-1007.

26. Huszar, D., R. Balling, R. Kothary, M. C. Magli, N. Hozumi, J. Rossant, and A. Bernstein. 1985. Insertion of a bacterial gene into the mouse germ line using an infectious retrovirus vector. Proc. Natl. Acad. Sci. USA 82:8587-8591.

27. Ikebuchi, K., G. G. Wong, S. C. Clark, J. N. Ihle, Y. Hirai, and M. Ogawa. 1987. Interleukin 6 enhancement of interleukin 3-dependent proliferation of multipotential hemopoietic progenitors. Proc. Natl. Acad. Sci. USA 84:9035-9039.

28. Jahner, D., K. Haase, R. Mulligan, and R. Jaenisch. 1985. Insertion of the bacterial gpt gene into the germ line of mice by retroviral infection. Proc. Natl. Acad. Sci. USA 82:6927-6931.

29. Johnson, P. A., and M. R. Rosner. 1986. Characterization of murine-specific leukemia virus receptor from L cells. J. Virol. 58:900-908.

30. Joyner, A., G. Keller, R. A. Phillips, and A. Bernstein. 1983. Retrovirus transfer of a bacterial gene into mouse haematopoietic progenitor cells. Nature (London) 305:556-558.

31. Kantofi, P. W., A. P. Gillio, J. R. McLachlin, C. Bordignon, M. A. Eglitis, N. A. Kernan, R. C. Moen, D. B. Kohn, S. F. Yu, E. Karson, et al. 1987. Expression of human adenosine deaminase in nonhuman primates after retrovirus-mediated gene transfer. J. Exp. Med. 166:219-234.

32. Keller, G., C. Paige, E. Gilboa, and E. F. Wagner. 1985. Expression of a foreign gene in myeloid and lymphoid cells derived from multipotent haematopoietic precursors. Nature (London) 318:149-154.

33. Kredich, N. M., and M. S. Hersfield. 1983. Immunodeficiency diseases caused by adenosine deaminase deficiency and purine nucleoside phosphorylase deficiency, p. 1157-1183. In J. B. Stanbury, J. B. Wyngaarden, D. S. Fredrickson, J. L. Goldstein, and M. S. Brown (ed.), The metabolic basis of inherited disease. McGraw-Hill Book Co., New York.

34. Kriegler, M., C. F. Perez, C. Hardy, and M. Botchan. 1984. Transformation mediated by the SV $40 \mathrm{~T}$ antigens: separation of the overlapping SV40 early genes with a retroviral vector. Cell 38:483-491.

35. Kwok, W. W., F. Schuening, R. B. Stead, and A. D. Miller. 1986. Retroviral transfer of genes into canine hemopoietic progenitor cells in culture: a model for human gene therapy. Proc. Natl. Acad. Sci. USA 83:4552-4555.

36. Lemischka, I. R., D. H. Raulet, and R. C. Mulligan. 1986. Developmental potential and dynamic behavior of hematopoietic stem cells. Cell 45:917-927.

37. Lim, B., D. A. Williams, and S. H. Orkin. 1987. Retrovirusmediated gene transfer of human adenosine deaminase: expression of functional enzyme in murine hematopoietic stem cells in vivo. Mol. Cell. Biol. 7:3459-3465.

38. Magli, M.-C., J. E. Dick, D. Huszar, A. Bernstein, and R. A. Phillips. 1987. Modulation of gene expression in multiple hematopoietic cell lineages following retroviral gene transfer. Proc. Natl. Acad. Sci. USA 84:789-793.

39. Mann, R., R. C. Mulligan, and D. Baltimore. 1983. Construction of a retrovirus packaging mutant and its use to produce helperfree defective retrovirus. Cell 33:153-159.

40. Markert, M. L., M. S. Hershfield, D. A. Wiginton, J. C. States, F. E. Ward, S. H. Bigner, R. H. Buckley, R. E. Kaufman, and J. J. Hutton. 1987. Identification of a deletion in the adenosine deaminase gene in a child with severe combined immunodeficiency. J. Immunol. 138:3203-3206.

41. Markowitz, D., S. Goff, and A. Bank. 1988. A safe packaging line for gene transfer: separating viral genes on two different plasmids. J. Virol. 62:1120-1124.

42. McIvor, R. S., M. J. Johnson, A. O. Miller, S. Pitts, S. R. Williams, D. Valerio, D. W. Martin, and I. M. Verma. 1987. Human purine nucleoside phosphorylase and adenosine deaminase: gene transfer into cultured cells and murine hematopoietic stem cells by using recombinant amphotropic retroviruses. Mol. Cell. Biol. 7:838-846.

43. Miller, A. D., and C. Buttimore. 1986. Redesign of retrovirus packaging cell lines to avoid recombination leading to helper virus production. Mol. Cell. Biol. 6:2895-2902.

44. Miller, A. D., R. J. Eckner, D. J. Jolly, T. Friedmann, and I. M. Verma. 1984. Expression of a retrovirus encoding human HPRT in mice. Science 225:630-632.

45. Miller, A. D., D. R. Trauber, and C. Buttimore. 1986. Factors involved in production of helper virus-free retrovirus vectors. Somat. Cell Mol. Genet. 12:175-183.

46. Mohandas, T., R. S. Sparkes, E. J. Suh, and M. S. Hershfield. 1984. Regional localization of the human genes for $S$-adenosylhomocysteine hydrolase (cen----q131) and adenosine deaminase (q131----qter) on chromosome 20. Hum. Genet. 66:292-295.

47. Petersen, M. B., L. Tranebjaerg, N. Tommerup, P. Nygaard, and H. Edwards. 1987. New assignment of the adenosine deaminase 
gene locus to chromosome $20 \mathrm{q} 13 \mathrm{X} 11$ by study of a patient with interstitial deletion 20q. J. Med. Genet. 24:93-96.

48. Rubenstein, J. L., J. F. Nicolas, and F. Jacob. 1984. Construction of a retrovirus capable of transducing and expressing genes in multipotential embryonic cells. Proc. Natl. Acad. Sci. USA 81:7137-7140.

49. Rubenstein, J. L., J. F. Nicolas, and F. Jacob. 1986. Introduction of genes into preimplantation mouse embryos by use of a defective recombinant retrovirus. Proc. Natl. Acad. Sci. USA 83:366-368.

50. Soriano, P., R. D. Cone, R. C. Mulligan, and R. Jaenisch. 1986 Tissue-specific and ectopic expression of genes introduced into transgenic mice by retroviruses. Science 234:1409-1413.

51. Southern, E. M. 1975. Detection of specific sequences among DNA fragments separated by gel electrophoresis. J. Mol. Biol. 98:503-517.

52. Stewart, C. L., M. Vanek, and E. F. Wagner. 1985. Expression of foreign genes from retroviral vectors in mouse teratocarcinoma chimaeras. EMBO J. 4:3701-3709.

53. Stuhlmann, H., R. Cone, R. C. Mulligan, and R. Jaenisch. 1984 Introduction of a selectable gene into different animal tissues by a retrovirus recombinant vector. Proc. Natl. Acad. Sci. USA 81:7151-7155.

54. Temin, H. 1986. Retrovirus vectors for gene transfer: efficient integration into and expression of exogenous DNA in vertebrate cell genomes, p. 149-188. In R. Kucherlapati (ed.), Gene transfer. Plenum Press, New York.

55. Thomas, P. S. 1980 . Hybridization of denatured RNA and small DNA fragments transferred to nitrocellulose. Proc. Natl. Acad. Sci. USA 77:5201-5205.

56. Vacha, J. 1983. Red cell life span, p. 67-132. In N. S. Agar and P. G. Board (ed.), Red blood cells of domestic mammals. Elsevier Science Publishers B.V., New York.
57. van der Putten, H., F. M. Botteri, A. D. Miller, M. G. Rosenfeld, H. Fan, R. M. Evans, and I. M. Verma. 1985. Efficient insertion of genes into the mouse germ line via retroviral vectors. Proc. Natl. Acad. Sci. USA 82:6148-6152.

58. Wagner, E. F., M. Vanek, and B. Vennstrom. 1985. Transfer of genes into embryonal carcinoma cells by retrovirus infection: efficient expression from an internal promoter. EMBO J. 4:663666.

59. Wiginton, D. A., D. J. Kaplan, J. C. States, A. L. Akeson, C. M. Perme, I. J. Bilyk, A. J. Vaughn, D. L. Lattier, and J. J. Hutton. 1988. Complete sequence and structure of the gene for human adenosine deaminase. Biochemistry 25:8234-8244.

60. Williams, D. A., I. R. Lemischka, D. G. Nathan, and R. C. Mulligan. 1984. Introduction of new genetic material into pluripotent haematopoietic stem cells of the mouse. Nature (London) 310:476-480.

61. Williams, D. A., S. H. Orkin, and R. C. Mulligan. 1986. Retrovirus-mediated transfer of human adenosine deaminase gene sequences into cells in culture and into murine hematopoietic cells in vivo. Proc. Natl. Acad. Sci. USA 83:2566-2570.

62. Yee, J. K., J. C. Moores, D. J. Jolly, J. A. Wolfi, J. G. Respess, and T. Friedmann. 1987. Gene expression from transcriptionally disabled retroviral vectors. Proc. Natl. Acad. Sci. USA 84: 5197-5201.

63. Yeung, C. Y., D. E. Ingolia, C. Bobonis, B. S. Dunbar, M. E. Riser, M. J. Siciliano, and R. E. Kellems. 1983. Selective overproduction of adenosine deaminase in cultured mouse cells. J. Biol. Chem. 258:8338-8345.

64. Yu, S. F., T. von-Ruden, P. W. Kantoff, C. Garber, M. Seiberg, U. Ruther, W. F. Anderson, E. F. Wagner, and E. Gilboa. 1986. Self-inactivating retroviral vectors designed for transfer of whole genes into mammalian cells. Proc. Natl. Acad. Sci. USA 83:3194-3198. 